\begin{tabular}{|c|c|}
\hline F & $\begin{array}{c}\text { International Journal of Current Research } \\
\text { and Academic Review }\end{array}$ \\
\hline $\begin{array}{l}\text { XCELLENT } \\
\text { UBLISHERS } \\
\text { UBL }\end{array}$ & $\begin{array}{c}\text { ISSN: 2347-3215 (Online) ,; Volume 5 ;, Number } 3 \text { (March-2017) } \\
\text { Journal homepage: http://www.ijcrar.com }\end{array}$ \\
\hline
\end{tabular}

doi: https://doi.org/10.20546/ijcrar.2017.503.010

\title{
Biosorption of Lead (II) and Nickel (II) from Dilute Aqueous Solution Using Fly ash as a Biosorbent
}

\author{
Haaris Ahsan Safdari ${ }^{1 *}$ and Mohd Kaifiyan ${ }^{2}$ \\ ${ }^{I}$ M.Sc. Biotechnology, Interdisciplinary Biotechnology Unit, Aligarh Muslim University, Aligarh, India \\ ${ }^{2}$ Senior Research Assistant (S.R.A, C.S.T. U.P. Project) Civil Engineering Section, Faculty of Engineering \& \\ Technology, Aligarh Muslim University, Aligarh, India \\ *Corresponding author
}

\section{Abstract}

Heavy metals are nonbiodegradable and exist in the environment create a threat to the organism due to their toxic nature removal and recovery of heavy metals from contaminated water is necessary with respect to environmental health and economical considerations. Heavy metals released in waste water from urban and industrial effluents, leakage of sewage pipes, and plumbing fixtures. For this several treatment technologies including adsorption, coagulation, flocculation, precipitation, reverse osmosis, biological process, ionizing, are being used. But many of these technologies are costly when they are used for treating large amounts of water from all of them the adsorption techniques are preferred because of their low cost, high efficiency, ease of operation. Fly ash a waste substance from thermal power plants is found in abundance utilization of fly ash as an adsorbent for the removal of heavy metals it helped reduce the environmental toxic metal burden and increased economic benefit. For this study, various factors affecting the removal of heavy metal ions, such as contact time with the solution, initial $\mathrm{pH}$ and adsorbent dose were investigated. The metal ion removal capacities of fly ash increased with increasing $\mathrm{pH}$ and a $\mathrm{pH}$ value was found to be the optimal $\mathrm{pH}$ for maximum metal removal capacity.
\end{abstract}

\section{Article Info}

Accepted: 28 February 2017

Available Online: 20 March 2017

\section{Keywords}

Biosorption,

Environment,

Fly ash,

Heavy metal.

\section{Introduction}

Heavy metals include lead $(\mathrm{Pb})$, nickel $(\mathrm{Ni})$, cadmium $(\mathrm{Cd})$, zinc $(\mathrm{Zn})$, mercury $(\mathrm{Hg})$, arsenic $(\mathrm{As})$, silver $(\mathrm{Ag})$ chromium $(\mathrm{Cr})$, copper $(\mathrm{Cu})$ iron $(\mathrm{Fe})$, and the platinum group elements. The presence of these metal ions in drinking water can cause severe diseases such as anemia, encephalopathy, and hepatitis etc. Heavy metals can be emitted into the environment by both anthropogenic and natural causes. The major causes of emission are the anthropogenic sources specifically mining operations, municipal solid waste, waste oil, metal plating facilities and tanneries (Musapatika et al., 2010). When people exposed to lead for a long time, they suffer from kidney, nervous system, reproductive system damages, etc. (Satya et al., 2012). Heavy metal discharge into aquatic ecosystems is a matter of concern. It is known that 11 metals namely $\mathrm{Pb}, \mathrm{Cr}, \mathrm{Hg}$, $\mathrm{Ur}, \mathrm{Se}, \mathrm{Zn}, \mathrm{As}, \mathrm{Cd}, \mathrm{Co}$ and $\mathrm{Ni}$ out of the 20 classified metals are referred to as toxic and are released into the environment in quantities which pose serious risks to human health (Jhonson et al., 2008; Bandela et al., 2016). Nickel is another heavy metal 
which is customarily confronted in raw waste water streams from industries such as electroplating, paint formulation, steam electric power plant and batteries. Nickel is responsible for cough, dermatitis, nausea, chronic asthma, cancer, leucopoenia and lymphopenia when injected (Rajurkar et al., 2016). There have been a number of techinques to remove heavy metals, including ion exchange (Ostroski et al., 2009) chemical precipitation Parmer et al., 2009; Bakar et al., 2009) membrane filtration (Samandari et al., 2013) and adsorption (Kursunlu et al., 2009; Narayan et al., 2009; Shanmugapriya et al., 2009) of these techniques, adsorption is considered to be one of the most suitable, easy to handle technique having high efficiency and cost effectiveness (Yedula et al., 2011; Monser et al., 2002). This study aims at investigating the utilization of fly ash as an adsorbent to remove lead $\mathrm{Pb}$ (II) and Nickel $\mathrm{Ni}$ (II) ions from aqueous solution, such as wastewater. As a matter of fact, a number of studies were undertaken to verify the influence of fly ash in the removal of heavy metal ions from aqueous solutions (Guptaa et al., 2000; Pehlivan et al., 2006; Papandreou et al., 2007; Wang et al., 2007). In this study, we report the investigation on the feasibility of fly ash to remove heavy metal ions $\left(\mathrm{Pb}^{2+} \& \mathrm{Ni}^{2+}\right)$ from water the adsorption process of heavy metal ions and investigation of the interactive effects of process parameters such as sorbent dose, contact time, solution $\mathrm{pH}$, and initial concentration on the adsorption capacity of coal fly ash towards the metal ions.

\section{Materials and Methods}

\section{Preparation of biosorbent}

The fly ash was collected from a Local Coal processing plant, sieved and washed several times with distilled water, and then dried in an oven at $100^{\circ} \mathrm{C}$ for 3 hours. The adsorbent was stored in a sealed bottle with a silica gel to prevent re-adsorption of moisture.

\section{Stock solutions}

Stock solutions of of Lead (II) and Nickel (II) metal ion were prepared by dissolving $(1000 \mathrm{mg} / \mathrm{l})$ analytical grade $\mathrm{Pb}\left(\mathrm{NO}_{3}\right)_{2}$ and $\mathrm{Ni}\left(\mathrm{NO}_{3}\right)_{2}$ with double distilled water. The solutions of varying concentrations were prepared by diluting the stock solutions with double distilled water.

\section{Effect of contact time}

The sorption process is strongly influenced by the contact time. For study of effect of contact time, $50 \mathrm{ml}$ of
$10 \mathrm{mg} / \mathrm{l} \mathrm{Lead}$ (II) and Nickel (II) solutions of varying $\mathrm{pH}$ were mixed with $0.5 \mathrm{mg}$ of flyash and stirred at different contact times. Then filtrate was analyzed for remaining metal ions.

\section{Effect of pH}

$50 \mathrm{ml}$ aqueous solution containing $10 \mathrm{mg} / \mathrm{L} \mathrm{Pb}$ (II) and $\mathrm{Ni}(\mathrm{II}), 1.2 \mathrm{mg}$ fly ash was added to conical flasks and the $\mathrm{pH}$-value was adjusted to $3,3.5,4,5,6,8$ and 10 . After 1 $\mathrm{h}$ shaking in the auto shaker at room temperature, with a speed of $150 \mathrm{r} / \mathrm{min}$, the sample was filtered and then filtrate was analyzed for remaining metal ions.

\section{Determination of optimum dosage of biosorbent}

To determine the optimum dosage of flyash, it was added to conical flask in different dosage containing known concentration of metal ion dosage. The solution in the conical flask was subjected to shaking for optimum contact time, filtered and analyzed for residual metal concentrations. The dosage that gave minimum residual concentration was chosen as optimum dosage.

\section{Biosorption studies}

Batch adsorption method was used for the removal of $\mathrm{Pb}$ (II) and $\mathrm{Ni}$ (II) ions were carried out at room temperature. Experiments were conducted in $100 \mathrm{ml}$ flasks containing $50 \mathrm{ml}$ of heavy metal solutions and ad the different biomass. The $\mathrm{pH}$ value was selected based on reported results indicating that high sorption of metal ions is attained for different $\mathrm{pH}$ values. The $\mathrm{pH}$ range chosen for the sorption is also based on avoiding metal precipitation and was adjusted to the required value with $0.1 \mathrm{~mol} / \mathrm{L} \mathrm{HNO}_{3}$ or $0.1 \mathrm{~mol} / \mathrm{L} \mathrm{NaOH}$ hourly, throughout the experiment. The mixtures were shaken on a rotary shaker (agitation rate, $200 \mathrm{rpm}$ ) for 2.5 hours, and then set still 1 hour to reach equilibrium. Then the biosorbent was filtered through an acid-cleaned $0.45 \mu \mathrm{m}$ Millipore filter and the concentrations of heavy metal ions in the filtrates were analyzed by flame atomic absorption spectrometer (Model GBC 932 Plus Australia). For the kinetic experiments, 25-200 $\mathrm{mg}$ of biomass was contacted with $50 \mathrm{ml}$ of the metal ion solutions of initial concentration between 10-100 mg/l, keeping the same conditions as described above. At scheduled time intervals, $8 \mathrm{ml}$ solution samples were drawn out and the concentrations of the residual heavy metals were analyzed. The depleted metal solutions were then analyzed to assess the metal concentration decline. Equilibrium isotherms were obtained using sample doses 
of and a range of initial metal concentrations between 10 and $100 \mathrm{mg} / \mathrm{l}$. The general procedure depicted above was followed, applying the same experimental conditions. The suspensions were stirred for the time required to attain equilibrium, as determined from kinetic measurements. Duplicate experiments were carried out for all the experiments. Average values are reported. In all the tests, metal and sorbent free blanks were also used for control.

\section{Results and Discussion}

\section{Effect of contact time}

Agitation time is one of the primary aspects while designing batch sorption systems for optimization of wastewater treatment plant. Fast sorption is among the main required parameters for successful usage of the biosorbent for practical application. Figure 1(a,b) \& $2(a, b)$ indicates the metal uptake by flyash as a function of time. An uptake capacity $60 \mathrm{mg} / \mathrm{g}(30 \mathrm{~min})$ of biosorbent was observed and then the sorption capacity increased constantly with increasing time. Beyond $90 \mathrm{~min}$, the percentage of biosorption is almost constant indicating the attainment of equilibrium conditions. The presence of sufficient external surface area on flyash may have increased the rate of biosorption in the initial stages, which was followed by a slower internal diffusion process, and may be the rate determining step. The equilibrium time was reached in $150 \mathrm{~min} 32 \mathrm{mg} / \mathrm{g}$ for $\mathrm{Ni}$ (II) \& $48 \mathrm{mg} / \mathrm{g}$ for $\mathrm{Pb}$ (II) respectively which was fixed as the optimum equilibrium time for the experimental runs. The increase observed in the uptake capacity with increase of contact time was due to availability of active sites on the biosorbent surface.

\section{Effect of Initial Metal Concentration and $\mathrm{pH}$ on Bisoroption}

The initial concentration of a metal is one of the main aspacts for the evaluation of biosorption of toxic metal ions within an aqueous system and provides an important driving force to overcome the hindrances faced while molecules are transferred between the liquid phase and solid phase. In this study, metal uptake capacity of $\mathrm{Pb}$ (II) and $\mathrm{Ni}$ (II) were investigated at biosorbent loading of 1.0 $\mathrm{gl}^{-1}$ for $\mathrm{Pb}(\mathrm{II})$ and 1.5 for $\mathrm{Ni}(\mathrm{II})$ respectively. The metal removal using flyash as biosorbent corresponding to different initial metal concentrations $10-80 \mathrm{mg} / \mathrm{l}$ for $\mathrm{Pb}$ (II) and $10-50 \mathrm{mg} / \mathrm{l}$ for $\mathrm{Ni}$ (II) are shown in figure 2(b). The increase in initial concentration of metals mentioned above resulted in the increased uptake capacity $\left(\mathrm{q}_{\mathrm{t}}\right)$ (29.56 to $48.48 \mathrm{mg} / \mathrm{g}$ for $\mathrm{Pb}$ (II) 14.86 to $33.18 \mathrm{mg} / \mathrm{g}$ for
$\mathrm{Ni}(\mathrm{II})$ respectively) and decreased percent removal (39.42-60.85 mg/g for $\mathrm{Pb}$ (II) and 52.16-36.18 mg/g for $\mathrm{Ni}(\mathrm{II}))$ respectively. The required driving force to counter the mass transfer hindrance of metal ions studied $(\mathrm{Pb}, \& \mathrm{Ni})$ between the liquid and the solid phase may be provided by the initial concentration of metal ions. An increase in heavy metal ion concentration also increases the interaction between the ions in the aqueous phase and the fly ash surface, which further resulted in higher uptake for the given mass of fly ash. The results revealed that at lower initial concentrations, all the ions interacted with the binding sites on the surface of biosorbent. At high initial concentrations, binding sites on the surface of flyash were saturated, with no further biosorption. A decrease in the sorption capacity was observed which was taken into consideration due to the repulsive forces between metal ions at related nearly sites on the surface of sorbent. The percentage removal of toxic metal ions by flyash was found to decrease with increase in initial metal concentration. The observed behavior can be corelated to the increase in the amount of toxic metal ions to the non-alteration of available active sites on the surface of biosorbent, but some metal ions were left in aqueous solution. Thus, it can be said that removal of metal ions studied are highly concentration dependent. $\mathrm{pH}$ is an another important factor affect the process of sorption. There was a change in the quantity of sorbed metal ions on the solid phase of flyash by increasing $\mathrm{pH}$ of the medium up to a maximum value of $\mathrm{pH}$ 5.2. for $\mathrm{Pb}$ (II) and 5.9 for $\mathrm{Ni}$ (II). At low $\mathrm{pH}$ values, the sorbent is positively charged, as the $\mathrm{pH}$ is lower than the isoelectric point. Hence the removal of metal ions was very low due to the electrostatic repulsion forces between positively charged $\mathrm{H}_{3} \mathrm{O}^{+}$and takes it metal ions. Thereafter, the sorption percentage decreased in alkaline medium, perhaps due to the formation of metal hydroxides and soluble hydroxyl complexes. Low $\mathrm{pH}$ depresses sorption of metal ions $(\mathrm{Pb} \& \mathrm{Ni})$ which is due to competition of metal ions with hydrogen ions bound to the biosorbent for forming part of the surface.

\section{Effect of biosorption loading}

The effect of biosorbent dosage on the sorption of metal ions $(\mathrm{Pb}$ (II) \& $\mathrm{Ni}$ (II) was investigated and was found that the percentage removal increases sharply with increasing dosage to a certain limit: $1.0 \mathrm{~g}$ for $\mathrm{Pb}$ (II) \& $1.5 \mathrm{~g}$ for $\mathrm{Ni}$ (II) respectively. Beyond these values, the percentage did not increased significantly. This phenomenon can be contributed to the larger availability of active sites on surface area of biosorbent making easier penetration of the metal ions to the biosorption sites of flyash. 
Fig.1 Effect of Initial metal concentration on removal of Ni(II) ions from aqueous solutions by flyash. Experimental Conditions: [pH: 5.9, biomass loading metal: $1.5 \mathrm{gl}-1$, T: $22{ }^{\circ} \mathrm{C}$, shaking speed: $120 \mathrm{rpm}$, contact time: $2.5 \mathrm{hrs}$ ]
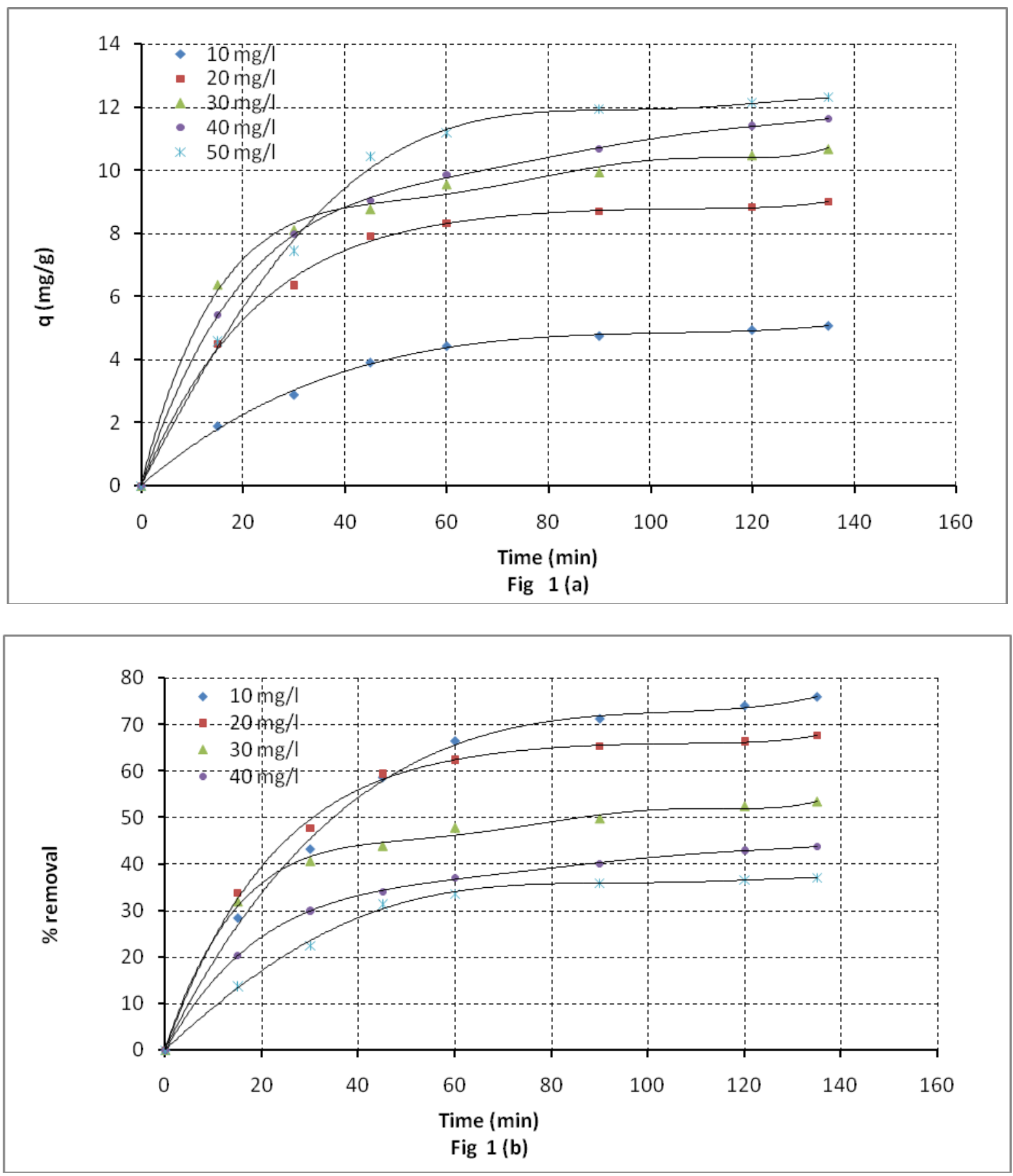
Fig.2 Effect of initial metal concentration on removal of $\mathrm{Pb}$ (II) ions from aqueous solutions by flyash.. Experimental Conditions: [pH: 5.2, biomass loading metal: $1.0 \mathrm{gl}-1$, T: $22{ }^{\circ} \mathrm{C}$, shaking speed: $120 \mathrm{rpm}$, contact time: $2.5 \mathrm{hrs}$ ]
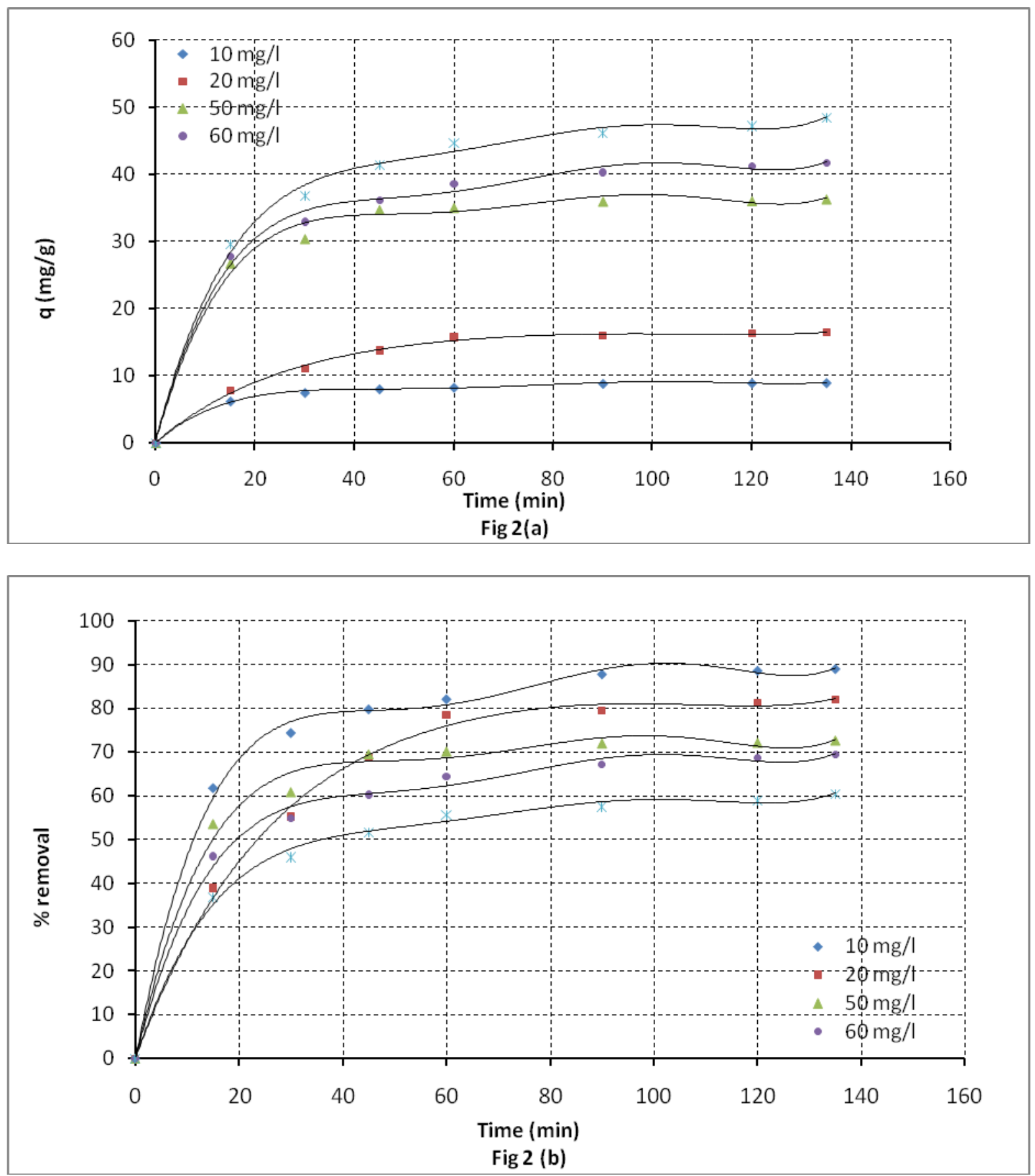

The dependence of $\mathrm{Pb}(\mathrm{II})$ and $\mathrm{Ni}$ (II) biosorption on dose was studied by varying the amount of biosorbents. The initial metal concentration $(100,80,60$ and $50 \mathrm{mg} / \mathrm{l})$, shaking speed $(120 \mathrm{rpm})$ and temperature $\left(22^{\circ} \mathrm{C}\right)$ were kept constant. The maximum uptake capacity for the metals under study by flyash was found to be 29.83 and $12.4 \mathrm{mg} / \mathrm{g}$ respectively. The dose of biosorbent has a significant impact on biosorption process. This suggests that after a certain dose of biosorbent, the maximum biosorption occurs in and therefore the amount of toxic metal ions attached to the biosorbent and the amount of free ions, do not change even with further addition of the dose. For dose of biosorbent used, there was an increase in percentage removal [48.48 to $64.17 \%$ for $\mathrm{Pb}(\mathrm{II})$, 
$23.47-44.62 \%$ for $\mathrm{Fe}(\mathrm{II})$ and $26.66-49.62 \%$ for $\mathrm{Ni}(\mathrm{II})]$. The quantity of biosorbent added to the aqueous solution evaluates the number of binding sites available for sorption of toxic metals. The decrease in the sorption capacity $(27.16-17.84 \mathrm{mg} / \mathrm{g}$ and $16.44-12.46 \mathrm{mg} / \mathrm{g}$ ) with the increasing biomass dose suggests that at constant concentration on increasing sorbent amount, the number of binding sites increases. Thus the effect of biosorbent dosage on percentage biosorption and uptake is considered to be an essential aspect. This forms an impact of partial aggregation, which occurs at higher dose of biosorbent $\&$ hence giving raise to decrease of active sites.

\section{Conclusion}

The ability of flyash as biosorbent was investigated for sorptive removal of $\mathrm{Pb}(\mathrm{II}), \& \mathrm{Ni}(\mathrm{II})$ ions from aqueous solutions. Various physio-chemical parameters such as $\mathrm{pH}$, initial metal ion concentration and equilibrium contact time were studied. The optimum solution $\mathrm{pH}$ for adsorption of metal ions from aqueous solutions was found to be $\mathrm{pH} 5.2$ for $\mathrm{Pb}(\mathrm{II})$, and 5.9 for $\mathrm{Ni}$ (II) and the optimum contact time was found to be $90-120 \mathrm{~min}$. The maximum capacity of flyash is $39.8 \& 32.6 \mathrm{mg} / \mathrm{g}$ respectively for the metal ions studied. This study revealed that flyash was an effective adsorbent for removal of metal ions from aqueous solutions.

\section{References}

Bakar, N., M. Bettahar, M. Bakar, S. Monteverdi, J. Ismail, M. Alnot. 2009. J. Mol. Catal. Chem., 308: 87-95.

Bandela, N.N., M.G. Babrekar, O.K. Jogdand, Geetanjali Kaushik. 2016. Removal of Copper from aqueous solution using local agricultural wastes as low cost adsorbent, J. Mater. Environ. Sci., 7(6): 1972-1978, ISSN: 2028-2508.

Guptaa, V.K., I. Ali. 2000. Utilisation of bagasse flyash (a sugar industry waste) for the removal of copper and zinc from wastewater, Separation and Purication Technol., 131-141.

\section{How to cite this article:}

Haaris Ahsan Safdari, Mohd Kaifiyan. 2017. Biosorption of Lead (II) \& Nickel (II) from Dilute Aqueous Solution Using Flyash as a Biosorbent. Int.J.Curr.Res.Aca.Rev. 5(3), 65-70.

doi: https://doi.org/10.20546/ijcrar.2017.503.010
Johnson, T.A., Jain, N., Joshi, H.C., Prasad, S. 2008. J. Sci. Ind. Res., 67: 647-658.

Kursunlu, A., E. Guler, H. Dumrw, O. Kocyigit, I. Gubbuk. 2009. J. Appl. Surf. Sci., 255: 8798-8808.

Monser, L., N. Adhoum. 2002. J. Sep. Purif. Techno., 26: 137-146.

Musapatika, E.T., M.S. Onyango, and Aoyi, O. 2010. Cobalt (II) removal from synthetic wastewater by adsorption on South African coal fly ash. South African J. Sci., 106: 9-10.

Narayan, N., M. Ganesan. 2009. J. Hazard. Mater., 161: 575-580.

Ostroski, I., M. Barros, E. Silva, J. Dantas, P. Arroyo, O. Lima. 2009. J. Hazard. Mater., 161: 1404-1412.

Papandreou, A., C.J. Stournaras, D. Panias. 2007. Copper and cadmium adsorption on pellets made from fired coal fly ash, J. Hazardous Materials, 110.

Parmer, K., H. Chaturvedi, S. Akhtar, S. Das, A. Pramanik, M. Ghosh, N. Bandopadhya. S. Bhattacharjee. 2009. Mater. Charact., 60: 863-868.

Pehlivan, E., S. Cetin, B.H. Yank. 2006. Equilibrium studies for the sorption of zinc and copper from aqueous solutions using sugar beet pulp and fly ash, J. Hazardous Materials, B135 193-199.

Rajurkar, N.S., Dipali Mahajan. 2016. Adsorption of Cobalt (II) and Nickel (II) Ions from Aqueous Solution on Chitosan, J. Chem. Biol. Physical Sci., Vol. 6, No. 4; 1203-1217, E- ISSN: 2249 -1929.

Samandari, S., M. Gazi, O. Yailmar. 2013. Water, Air Soil pollut., 224: 1624-1635.

Satya Vani Yadla, V., Sridevi, M.V.V., Chandana Lakshmi. 2012. Adsorption Performance of Fly Ash For The Removal of Lead, Int. J. Engi. Res. Technol., (IJERT), Vol. 1 Issue 7, ISSN: 2278-0181

Shanmugapriya, A., M. Hemlatha, A. Augastine. J. Der. Pharma Chemica, 5(3): 141-155.

Wang, S.B., T. Terdkiatburana, M.O. 2007. Tade, Single and co-adsorption of heavy metals and humic acid on fly ash, Separation and Purication Technol., 1-6.

Yedula, R., C. Balamajumde. 2011. Res. J. Chem. Sci., 30-39. 